\title{
Assessing the economic viability of the plastic biorefinery and its contribution to a more circular plastic sector
}

\author{
Megan Roux, Cristiano Varrone *
}

\author{
Affiliation: Section for Sustainable Biotechnology, Department of Chemistry and BioScience, Aalborg \\ University. A. C. Meyers Vænge 15, C2, 2450 Copenhagen SV, Denmark; cva@bio.aau.dk \\ * Correspondence: cva@bio.aau.dk
}

\begin{abstract}
It is widely accepted that plastic waste is one of our most urgent environmental concerns the world is currently facing. Plastic has contributed greatly to innovation in all fields, but the raw material for its production (fossil fuels), as well as the linear economy in which it is currently produced and used, makes the material problematic from a sustainability and human health perspectives. The emergence of bio-based plastics provides an opportunity to reduce dependency on fossil fuels and transition to a more circular plastics economy. For polyethylene terephthalate (PET), one of the most prevalent plastics in packaging and textiles, there exist two bio-based alternatives that are similar or superior in material property and recyclability. These are polyethylene furanoate (PEF) and polytrimethylene terephthalate (PTT). The overarching aim of this study was to examine the transition from fossil-based to renewable plastics, through the lens of PET upcycling into PEF and PTT. The process for the production of PEF and PTT from three feed streams (post-consumer PET waste, lignocellulosic biomass-derived cellulose and biodiesel-derived crude glycerol) was developed in the software SuperPro Designer and the economic viability assessed via a discounted cumulative cash flow (DCCF) analysis. This study represents a conceptual case study of the valorisation of existing plastic waste into new, recyclable bio-based plastics, for a more sustainable plastics production. A techno-economic analysis of the designed process revealed that the minimum selling price (MSP) of second generation-derived PEF and PTT is $3.13 \mathrm{USD} / \mathrm{kg}$, and that utilities and the feedstock used for the production of 2,5-furandicarboxylic acid (FDCA) needed in PEF synthesis contributed the most to the process operating costs. The effect of recycling PEF and PTT through the process at three recycling rates (42\%, 50\% and 55\%) was investigated and revealed that increased recycling could reduce the MSP of the 2G bio-plastics (by $48.5 \%$ ) to 1.61 USD $/ \mathrm{kg}$. This demonstrates that increasing recycling rates would have a beneficial effect on the economic viability of the plastic biorefinery.
\end{abstract}

Keywords: bio-based plastic; circular plastic economy; biorefinery; techno-economic analysis; polyethylene terephthalate; polyethylene furanoate; polytrimethylene terephthalate

\section{Introduction}

The projected amount of global plastic waste is 500 million tonnes by 2030, of which the majority is food packaging, comprising $60 \%$ of all coastal waste [1]. This has severe detrimental effects on the environment and human health. However, plastic is useful in a wide range of applications and results in lower $\mathrm{CO}_{2}$ emissions from transportation when compared to glass [2]. A system for the production and use of plastics that is more circular in nature - namely the circular economy - will result in a decrease in plastic production and waste [3]. In this system, the majority of plastic should be reusable or recyclable. 
However, the recycling of plastic is hindered by several barriers, including high collection costs, a wide range of polymers with different properties, and the fact that plastic products are often designed with functionality in mind instead of end-of-life scenarios [4]. Recycling plastic is also not considered to be economically viable as a result of virgin plastic being cheaper than recycled plastic, and a lack of market demand for recycled plastic [4]. In fact, it is estimated that $95 \%$ of the value of plastic packaging material is lost already after the first use [5].

Mechanical recycling, which is the most common recycling method employed currently, results in a loss of plastic molecular mass, and so the number of times an item of plastic can be recycled mechanically is limited [6]. Additionally, large fractions of mixed plastic waste and multilayer materials cannot be mechanically recycled [7]. In addition to limiting the amount of plastic produced, the resources for new plastics production should be renewable so as to reduce dependency on non-renewable resources like fossil fuels [5], as it is expected that plastic's contribution to global oil consumption will increase from the current $4-8 \%$ to $20 \%$ in 2050 [2]. The production of plastics made from renewable resources, bio-based plastics, is expected to increase from 2.11 million tonnes in 2020 to 2.87 million tonnes by 2025 [8]. In addition, the EU is increasing investment in bioplastics and aims to replace $30 \%$ of fossil-based plastic food packaging with bioplastic [9]. PET is a fossil-based plastic that is widely used in packaging and textiles, and is also one of the most recycled plastics [10], with an estimated production of 70 million tonnes per annum [11]. Due to the depletion of non-renewable resources, like the petroleum used to make conventional plastics, there is increasing focus on plastics made from renewable material [14]. It would therefore be interesting to identify bio-based polymers with similar properties to PET which have the potential to substitute it. Polyethylene furanoate (PEF) is a bio-based plastic that is considered closest to PET with respect to thermal and mechanical properties. PEF is considered a superior polymer to PET for packaging, as a result of a higher glass transition temperature, $\mathrm{T}_{\mathrm{g}}$, when compared to PET $\left(82-87^{\circ} \mathrm{C}\right.$ for PEF and $71-75^{\circ} \mathrm{C}$ for PET) [12]. In addition, PEF has several properties that make it superior to PET for the production of plastic bottles. The lower melting temperature, $\mathrm{T} \mathrm{m}$, of PEF $\left(210-215^{\circ} \mathrm{C}\right)$ compared to PET $\left(246^{\circ} \mathrm{C}\right)$ makes extrusion and blow moulding of the material easier. The Young's modulus and strength of PEF is higher than for PET, which allows for thinner bottle walls [12] and a more resilient material [15]. And finally, PEF has excellent $\mathrm{O}_{2}$ and $\mathrm{CO}_{2}$ gas barrier properties, with PEF being 31 times less permeable to carbon dioxide than PET is. Like PET, PEF has a high thermal stability up to around $350{ }^{\circ} \mathrm{C}$ [15]. Eerhart et al. [16] compared the energy use and greenhouse gas (GHG) emissions for PEF and PET production, and found that completely replacing PET plastic bottles with bio-based PEF ones can save between 440 and 520 PJ of non-renewable energy use, and result in a reduction of GHG emissions of 20-35 Mt of $\mathrm{CO}_{2}$ equivalent. Thus, PEF seems to represent an excellent example of a bio-based plastic that can replace PET in the food packaging sector as part of the transition to a circular plastics economy.

As mentioned above, PET is also widely used in the textile industry. PTT can be a bio-based alternative to PET that can be used in textiles and potentially also for packaging. PTT has a $\mathrm{T}_{\mathrm{g}}$ of $50{ }^{\circ} \mathrm{C}$ and $\mathrm{T}_{\mathrm{m}}$ of $228^{\circ} \mathrm{C}$ [17] and displays excellent properties that make it superior to PET in fibre applications. The polymer can be dyed at higher temperatures $\left(100^{\circ} \mathrm{C}\right)$ than PET, which simplifies the dyeing process. PTT fabric that has been dyed has a better colour fastness, and shows deeper shades than PET fabric [17].

The plastic is made similarly to PET, by polymerisation with terephthalic acid (PTA) and 1,3-propane diol (PDO) in place of EG. This means that it could easily be produced in already existing PET production sites [18]; moreover, the overall PTT polymerisation process is more energy efficient than for PET, leading to lower $\mathrm{CO}_{2}$ emissions [13]. Advances in cost-effective bio-based PDO production as well as the refinement of continuous polymerisation processes have allowed for the economical production of highquality PTT, resulting in the commercialisation of the polymer by DuPont and by Shell. 
PTT is also known by its commercial name, Sorona ${ }^{\circledR}$ (DuPont) [17], or Corterra (Shell). Overall, the energy efficiency of the PTT production process is greater than for PET production, as PTT polymerisation and downstream processing requires less energy than for PET [17]. Moreover, PDO can be produced through bioconversion of waste streams, such as biodiesel-derived crude glycerol [19]. Notably, PEF has been shown to be easier to biodegrade and depolymerize than PET [15]. This represents a key element for a more circular plastic industry, since an efficient and easier depolymerization potentially allows for infinite recycling. Until now, very few studies have investigated PTT biodegradation, but it has been reported that PTT can be enzymatically hydrolyzed using diverse enzymes also used for PET depolymerisation [20]. Moreover, the longer (and uneven) diol chain and lower glass transition of PTT should, in principle, facilitate degradation compared to PET [21]. Could we then imagine using post-consumer PET waste as a source for more carbon-neutral substitutes, such as PEF and PTT?

When depolymerised, PET forms EG and PTA. These monomers can be used to make a range of materials, including new plastics. The synthesis of PEF requires EG, and the synthesis of PTT requires PTA. Thus, PET waste can be turned into valuable, renewable and bio-based plastics with improved properties, which is in essence the concept of a biorefinery and bio-upcycling. In this sense, we might define this process as a 'plastic biorefinery' (Fig.1). The proposed basic steps involved in the transformation of PET waste into PEF and PTT are: PET depolymerisation, PEF synthesis (with the addition of biobased FDCA), and PTT synthesis (with the addition of bio-based PDO).

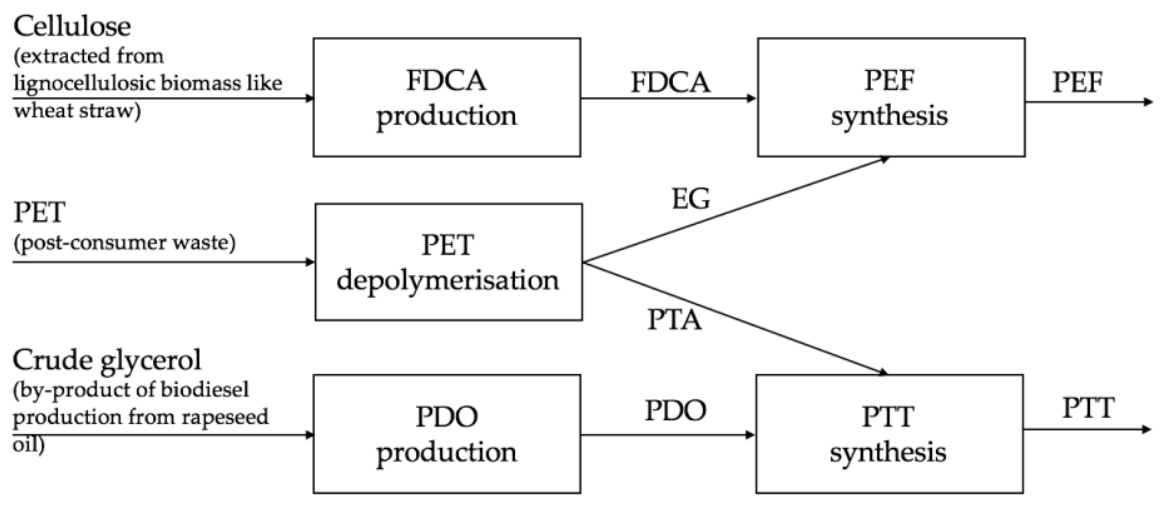

Figure 1. Block flow diagram showing the concept and material flow of the PET plastic biorefinery: three waste streams (biodiesel-derived crude glycerol, post-consumer PET and lignocellulosic biomass-derived cellulose) can be used to synthesise PEF and PTT.

The present work represents a case study to assess the contribution and economic viability of a 'plastic biorefinery' to the transition towards a more sustainable and circular plastic industry. This novel approach proposes to integrate biochemical recycling of fossilbased plastic waste together with (2G) bio-based building blocks to produce more carbonneutral polymers that are easier to recycle.

\section{Materials and Methods}

\subsection{Simulation and assumptions}

The plastic biorefinery concept was designed from established processes found in literature. The process was then modelled in the software SuperPro Designer (version 9.5) using the information obtained from this literature. Continuous operation was chosen with a time on stream of 7920 hours per annum. The processing rate is 68000 tonnes per annum (tpa) of post-consumer waste PET. It is assumed that this PET is the residual plastic that is not recycled [12]. 


\subsection{Process design}

The block flow diagram in Figure 1 describes the overall concept of the 'plastic biorefinery' in which post-consumer waste PET is upcycled into PEF and PTT. A detailed diagram of the process is shown here in Figure 2, representing the 12 main operations and the 28 streams associated with it. The process is divided into five principal. In Area 1, PET is enzymatically depolymerised into EG (stream 7) and PTA (stream 18), and these monomers are purified. Sodium sulfate $\left(\mathrm{Na}_{2} \mathrm{SO}_{4}\right)$ is also formed and is sold (stream 6). In Area 2, FDCA is produced from lignocellulosic biomass-derived cellulose (stream 8), via the formation of 5-hydroxymethylfurfural (HMF). In Area 3, FDCA from Area 2 is converted to its dimethyl ester form (DMFD) before being added to EG from Area 1 to synthesise PEF (stream 17). In Area 4, PDO is formed from biodiesel-derived crude glycerol (stream 19) and purified. In Area 5, PTA is converted to its dimethyl ester form (DMT) and then used with PDO from Area 4 to synthesise PTT (stream 26).

Specifics of this process are described further in the Methods section, and the flow rates for the streams shown in the figure can be found in Tables S5 (a) and (b) in the electronic supplementary information.

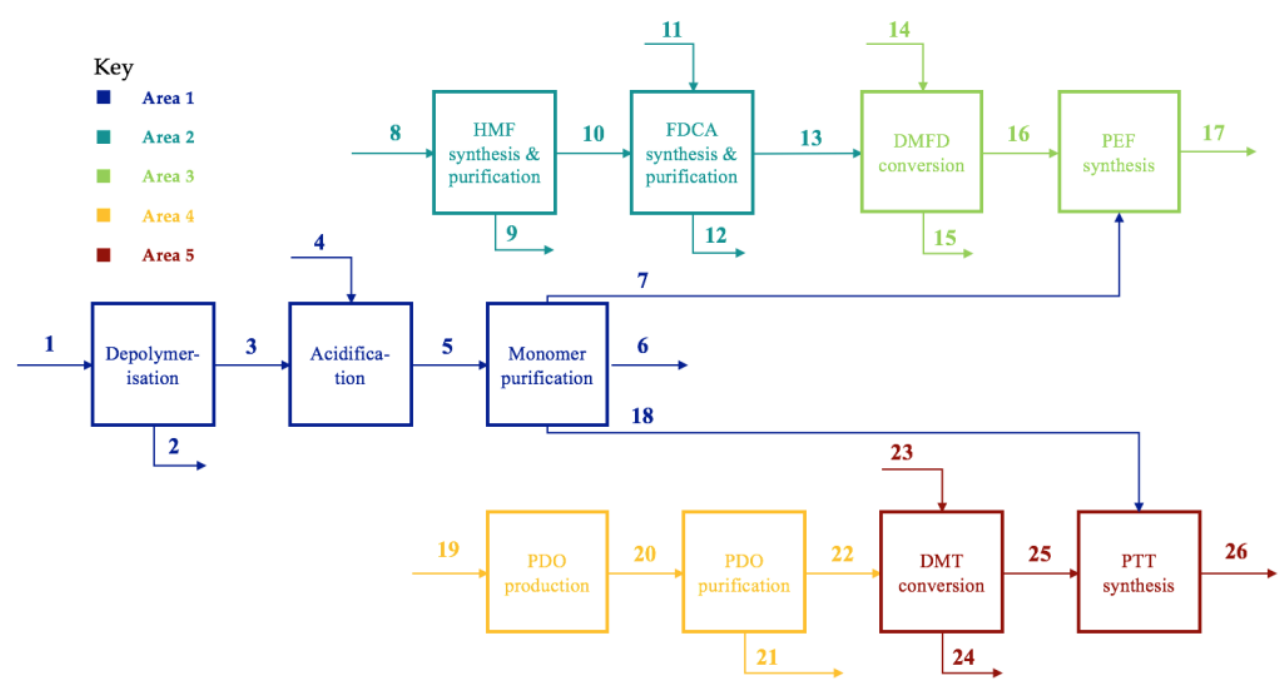

Figure 2. Expanded block flow diagram of the plastic biorefinery concept. Area 1: PET depolymerisation and purification of monomers, Area 2: FDCA production from cellulose, 3) PEF synthesis, 4) PDO production from crude glycerol, and 5) PTT synthesis.

\subsubsection{Area 1: PET depolymerisation}

In Area 1, PET is enzymatically depolymerised and the resulting monomers purified for use in Areas 3 and 5. The PET depolymerisation process was designed based on the latest and most advanced process found in literature [12], developed by Carbios and the University of Toulouse. The purification of the monomers was taken from the process described by Ügdüler et al. [11]. PET is thus depolymerised using a leaf-compost cutinase (LCC) enzyme in a batch reactor, forming EG and sodium terephthalate $\left(\mathrm{Na}_{2} \mathrm{TP}\right)$. The residual PET is removed by filtration and pigment is removed by adsorption. The $\mathrm{Na}_{2} \mathrm{TP}$ is then acidified with sulfuric acid $\left(\mathrm{H}_{2} \mathrm{SO}_{4}\right)$ to form PTA and sodium sulfate $\left(\mathrm{Na}_{2} \mathrm{SO}_{4}\right)$. Finally, PTA is purified from this stream by filtration and crystallisation. EG is then removed by flash separation and distillation, and the $\mathrm{Na}_{2} \mathrm{SO}_{4}$ formed can be sold. 
Table 1. Specifications for mass balances and conversions in Area 1.

\begin{tabular}{ccc}
\hline Parameter & Value & Source \\
\hline PET flow rate & $67853 \mathrm{tpa}$ & Calculated \\
Enzyme loading & $0.2 \mathrm{wt} . \%$ & {$[11]$} \\
PET conversion & $90.0 \%$ & {$[11]$} \\
PTA yield & $86.3 \%$ & {$[11]$} \\
\hline
\end{tabular}

\subsubsection{Area 2: FDCA synthesis}

FDCA synthesis was modelled according to the process described by Kim et al. [22]. In this process, cellulose is directly dehydrated to 5-hydroxymethylfurfural (HMF) using a tetrahydrofuran (THF) solvent and $\mathrm{H}_{2} \mathrm{SO}_{4}$ catalyst. Lime is added to neutralise the acid, after which THF is recovered by distillation and recycled in the process. Humins and other byproducts are removed by activated carbon adsorption, and HMF is converted to FDCA using gamma-valerolactone (GVL) as a solvent and $\mathrm{Pt} / \mathrm{C}$ as a catalyst. FDCA is purified by solid-liquid separation and GVL is recycled in the process. Levulinic acid (LA), formed as a byproduct in HMF production, is used to synthesise make-up GVL lost in the FDCA reactor.

Table 2. Specifications for mass balances and conversions in Area 2.

\begin{tabular}{ccc}
\hline Parameter & Value & Source \\
\hline Cellulose flow rate & $131900 \mathrm{tpa}$ & Calculated \\
Cellulose loading & $3.0 \mathrm{wt} \%$ & {$[22]$} \\
HMF yield & $42 \mathrm{~mol} \%$ & {$[22]$} \\
FDCA yield & $93.6 \mathrm{~mol} \mathrm{\%}$ & {$[22]$} \\
FDCA recovery & $95 \%$ & {$[22]$} \\
\hline
\end{tabular}

\subsubsection{Area 3: PEF synthesis}

PEF can be synthesised by a number of means, although the process in this study is based on transesterification as described by Kasmi et al. [17]. First, FDCA is esterified to the dimethyl ester of FDCA (DMFD). This is done by reacting FDCA with methanol, where excess methanol is removed by distillation and recycled in the process. DMFD is then cooled and purified by microfiltration and crystallisation. DMFD and EG from Area 1 are then mixed together in a pasting unit before polymerisation in three stages on a tetrabutyl titanate (TBT) catalyst: transesterification, pre-polymerisation and polycondensation, during which PEF is formed at high temperatures and vacuum conditions. Methanol is formed as a byproduct and is removed from excess EG by distillation, and both components are recycled in the process. The PEF molecular weight is further increased by extruding, cooling and cutting the polymer before a final polymerisation step, solid state polymerisation (SSP) at high temperature and vacuum conditions.

Table 3. Specifications for mass balances and conversions in Area 3.

\begin{tabular}{ccc}
\hline Parameter & Value & Source \\
\hline FDCA conversion & $83 \%$ & {$[17]$} \\
PEF purity & $99.4 \%$ & Calculated \\
PEF flow rate & $59150 \mathrm{tpa}$ & Calculated \\
\hline
\end{tabular}

\subsubsection{Area 4: PDO synthesis}

In Area 4, the PDO required for PTT synthesis with PTA is formed by fermentation of crude glycerol obtained as a byproduct from biodiesel production, following the highly 
efficient bioconversion process described by Chatzifragkou et al. [23]. In this section of the process (Area 4), Clostridium butyricum cells are cultivated in shake flasks before being used in a series of fermentation reactors of increasing size, to which crude glycerol and fermentation medium is added. The fermentation under non-sterile conditions occurs in a fed-batch process, and results in the production of $67.9 \mathrm{~g} / \mathrm{L}$ [23]. The PDO formed in these fermentation reactors is purified by filtration, ion exchange and evaporation, as described by Petrides et al. [24].

Table 4. Specifications for mass balances and conversions in Area 4.

\begin{tabular}{ccc}
\hline Parameter & Value & Source \\
\hline Crude glycerol flow rate & 64550 tpa & Calculated \\
Crude glycerol purity & $81 \%$ & {$[23]$} \\
Crude glycerol in feed & $75 \%$ & {$[23]$} \\
Crude glycerol flow rate & 64550 tpa & {$[23]$} \\
PDO purity & $99.3 \%$ & Calculated \\
\hline
\end{tabular}

\subsubsection{Area 5: PTT synthesis}

Considering the similarities in properties and process routes between PTT and PET , PTT synthesis modelling was based on the PET synthesis process. In this Area, PTA is esterified to dimethyl phthalate (DMT) in place of FDCA to DMFD conversion.

\subsection{Cost estimations and cash flow analysis}

Capital and operating cost estimations were extracted from the model, and a discounted cumulative cash flow (DCCF) analysis was performed using chemical engineering heuristics [25] and following the procedure set up by a National Renewable Energy Laboratory (NREL) technical report [26], with factors localised to the Danish context. Detailed information regarding the major inputs to the model and DCCF analysis can be found in the electronic supplementary material (Tables S1 and S2, respectively). Further descriptions regarding the basic calculations used by SuperPro Designer to perform the economic evaluation are available in [27].

\section{Results}

The designed process resulted in the production of 59000 and 53000 tpa PEF and PTT respectively, from waste streams of 68000 tpa PET, 132000 tpa cellulose and 65000 tpa crude glycerol.

The MSP of PEF and PTT was calculated using a DCCF analysis, and this was compared to the selling price (SP) of conventional PET. The capital and operating costs of the process (Table S3) were then examined to highlight any bottlenecks or areas for potential optimisation, and a sensitivity analysis was performed to determine the parameters that could have significant effects on the process.

\subsection{Minimum selling price}

More in detail, a DCCF analysis was used to estimate the MSP of PEF and PTT required for a net present value (NPV) of zero, after ten years of operation. The NPV is the DCCF value after a defined period of time, and when the NPV is zero it indicates the break-even point. The MSP is calculated as the minimum price at which a product must be sold so as to make the process profitable (where the NPV is zero) after a defined period of time.

Two scenarios were compared: 1) producing FDCA from a 2G cellulose feedstock, and 2) directly purchasing FDCA, at a price of $1.90 \mathrm{USD} / \mathrm{kg}$ [14]. For the latter, it is assumed that the FDCA is produced from fructose or high fructose corn syrup (HFCS), as is the most common feedstock for current FDCA production [12]. HFCS was not used as 
the feedstock for Scenario 1 in this study as it is a first generation (1G) feedstock, which could result in competition with food production. Second generation $(2 \mathrm{G})$ feedstocks such as waste streams from other sectors - are preferred. Details about the DCCF of Scenario 1 are provided in Table S4, while the most important process streams (in kgh) are shown in Table S5.

In order to assess the minimum selling price, PEF and PTT selling price was set as 2.70 USD $/ \mathrm{kg}$, which is the estimated production cost of PEF [28].

Table 5. Selling price (SP), payback period (PBP) and MSP of scenario $1 \& 2$.

\begin{tabular}{ccc}
\hline & Scenario 1 & Scenario 2 \\
\hline SP (USD $/ \mathrm{kg})$ & 2.70 & 2.70 \\
PBP (years) & 23.3 & 5.15 \\
MSP (USD $/ \mathrm{kg}$ ) & 3.13 & 2.34 \\
\hline
\end{tabular}

The MSPs of Scenario 1 (where FDCA is produced on-site from cellulose) and Scenario 2 (where FDCA is purchased directly) are 3.13 and $2.34 \mathrm{USD} / \mathrm{kg}$ respectively. When compared to the selling price of PET, which is estimated between 0.725 and 0.950 USD $/ \mathrm{kg}$ [29], it is seen that these plastics are not directly economically competitive with PET when produced via the designed process. On the other hand, Sorona ${ }^{\circledR}$ PTT (by DuPont) is sold for $4.00 \mathrm{EUR} / \mathrm{kg}$ (4.66 USD $/ \mathrm{kg}$ ) [30], suggesting that the PTT produced through the PET biorefinery could be economically viable. This indicates that there is a market for these more expensive bio-based alternatives to PET, even though it is questionable whether they would be able to substitute PET on a larger scale, at the moment. Considering that PEF is not currently commercially available, it is challenging to estimate how much the polymer will be sold for on the market.

Table 5 shows that Scenario 2, where HFCS-derived FDCA is purchased and used for PEF synthesis, is more profitable. However, as mentioned above, this would make use of first generation feedstocks. In general, and as part of the circular economy approach, the utilisation of residual streams is preferred so as to not compete with food production, while avoiding accumulation (and mismanagement) of waste.

The payback period (PBP) for both scenarios was also determined. The PBP is calculated as the fixed capital investment over the average cash flow. This is an indication of how long it would take for investors to earn back their investment. Obviously, the lowest possible PBP is desired, and investors may be unwilling to invest if the projected PBP is decades long, which further highlights that Scenario 2 is the preferred solution from an economic perspective.

However, as mentioned, the valorisation of waste streams is preferred in a biorefinery and circular economy concept. Therefore, in the next section, the capital and operating costs of Scenario 1 will be further investigated to identify areas of the process that can be improved to make PEF and PTT production from waste streams more economically viable. 


\subsection{Capital and operating costs in Scenario 1}

To understand the process hot-spots and identify areas of optimisation, so as to improve the profitability of the 2G-based process and make PEF and PTT more economically competitive with PET, Scenario 1 was further examined (Fig.3).

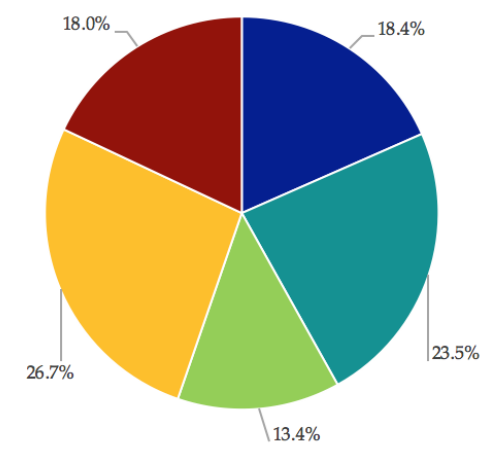

(a)

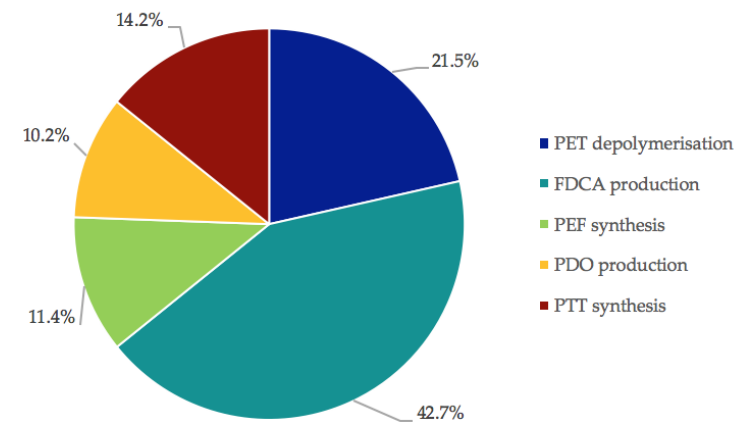

(b)

Figure 3. Distribution of capital costs (a) and operating costs (b) between the process Areas of Scenario 1. PET depolymerization $=$ Area $1 ;$ FDCA production $=$ Area 2; PEF synthesis $=$ Area 3; $\mathrm{PDO}$ production $=$ Area 4 ; PTT synthesis = Area 5 .

While the capital costs are rather evenly distributed among all areas, it is clearly seen that Area 2 (FDCA production) contributes disproportionately to the operating costs. Consequently, the operating costs within Area 2 were thus further examined, and are shown in Figure 4.

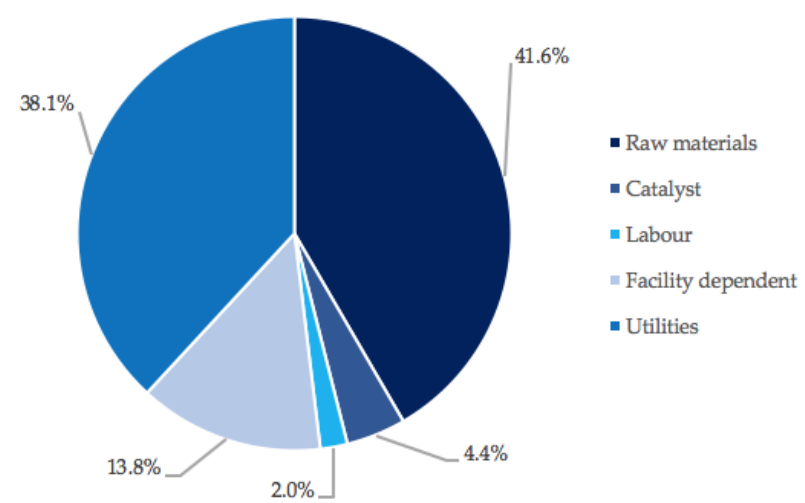

Figure 4. Breakdown of Area 2 operating expenses.

As it is seen, raw materials and utilities contributed most to the Area operating costs (with $41.6 \%$ ). Within raw materials, cellulose contributed $94 \%$. This high cost of the feedstock is likely due to the processing of lignocellulosic material required to extract the cellulose. This can represent a challenge when using second generation feedstocks, as the lower cost of the initial feedstock does not always overcome the cost associated with processing the complex/recalcitrant material into a usable form.

On the other hand, FDCA can be produced from a number of feedstocks and via a number of process routes [13]. For example, FDCA can be produced from pectins - which can be extracted from residual streams like sugar beet pulp and citrus peels - via the formation of 2-formyl-5-furoic esters instead of via HMF [31]. Another study has demonstrated that HMF can be produced from the simultaneous conversion of glucose and xylose to HMF and furfural [32], thus increasing the overall HMF yield and allowing 
for more of the feedstock to be exploited. For example, using a wheat straw feedstock, which contains both glucose and xylose, with this method, means that almost all of the substrate could be used instead of only the glucose-containing part of the feedstock. However, these routes have yet to be assessed on an industrial scale and were therefore not used in this study, but could provide an alternative to the challenge of sustainable and viable FDCA production in the future.

Last but not least, Fig. 4 also shows that utilities constituted the second largest contribution to Area 2 operating costs (with 38.1\%). This was mostly due to the requirement of high pressure steam for the cellulose conversion reactor, where high temperatures $(483 \mathrm{~K})$ are required. This contribution could be mitigated by heat integration across the process (because the re-use of heat generated inside the process can reduce the need for external energy consumption, such as electricity and steam [33]) or the development of efficient biological processes that operate at milder conditions.

\subsection{Sensitivity analysis}

A sensitivity analysis of a process reveals which factors affect the process the most. Figure 5 shows a sensitivity analysis for the process, used to assess the impact that possible changes (within a certain range) of such key factors would have on the profitability of the process. To this purpose, cost driving parameters like price of cellulose, catalyst, enzyme, utilities, as well as the tax rate, were changed to $50 \%$ below and above the base-case values.

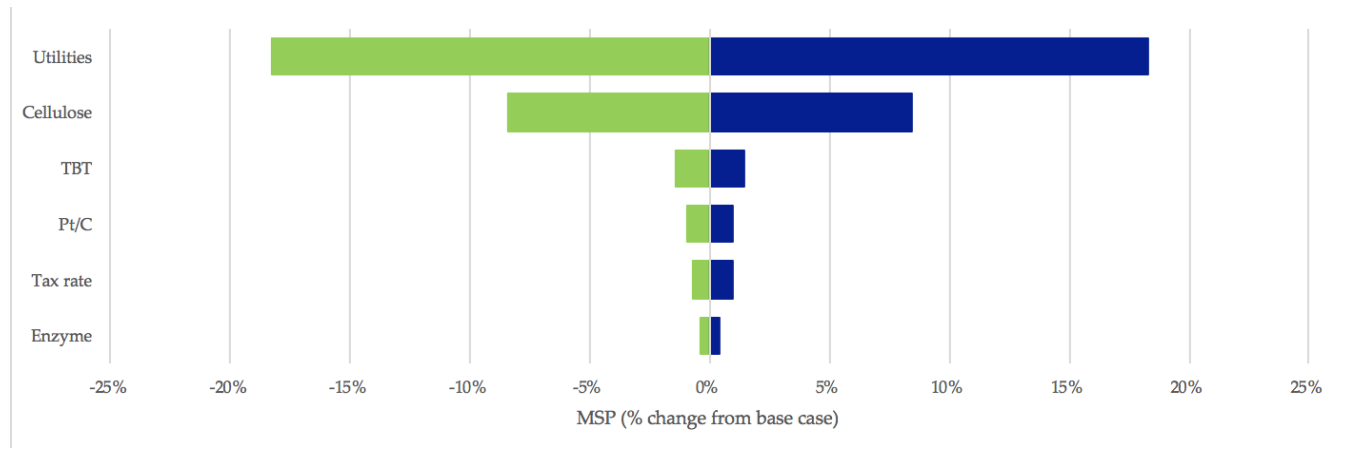

Figure 5. Sensitivity analysis of Scenario $1 . \mathrm{TBT}=$ tetrabutyl titanate, the catalyst used in PEF and PTT synthesis; $\mathrm{Pt} / \mathrm{C}=$ the catalyst used in cellulose-to-HMF conversion.

As can be seen in Figure 5, the process is most sensitive to a change in price of utilities, which contributes to $35 \%$ of the overall operating costs of the process. Increasing the overall utilities costs by $50 \%$ would result in an MSP of $3.70 \mathrm{USD} / \mathrm{kg}$ (instead of 3.13 $\mathrm{USD} / \mathrm{kg}$ ). To minimise the contribution of utilities to the process, plant-wide heat integration should be implemented and could result in an MSP of $2.58 \mathrm{USD} / \mathrm{kg}$ (when utilities consumption is reduced by half). This would have both economic and environmental benefits.

As expected from the breakdown of operating costs over Area 2, the price of cellulose has also a significant impact on the process. The catalysts used in PEF and PTT synthesis (Areas 3 and 5) and in the cellulose-to-HMF conversion (Area 2) have the next greatest impacts on the process.

\subsection{The contribution of policies to a more circular plastic sector}

A recent study by Fernando Foncillas et al. [34] underlined the importance of public subsidies in the development of economically viable biorefineries. Clearly, dedicated subsidies could facilitate the transition towards $2 \mathrm{G}$ plastic biorefineries as well, thus supporting the bio-based economy. Moreover, policy targets and increasing recycling rates may also affect the economic viability of PEF and PTT. It is therefore important to investigate the potential impact of such policies. In 2015, the European Commission 
proposed that at least $55 \%$ of all plastics packaging should be recycled by 2025 [35], although it was estimated that only $42 \%$ of plastic was recycled in the European Union in 2017 [36]. How would those recycling rates affect the plastic biorefinery economy? Fig.6 shows different recycling scenarios for the upcycled PEF and PTT $(0 \%, 42 \%, 50 \%$ and $55 \%)$ and their effect on the MSP.

It was assumed in these scenarios that PEF and PTT are recycled and therefore less FDCA and PDO are required. Thus, the following assumptions were made:

- PEF and PTT are depolymerised and the monomers purified in the same way as PET

- Less PET is produced (and therefore recycled) as PEF and PTT replace it

- Area 1 functions as normal

- Area 2 and 4 have less throughput (adjusted to meet the EG and PTA output from PET depolymerisation)

- Area 3 and 5 have slightly less throughput

Implementing these into the model, it can be seen that increasing recycling has a significant effect with a clear trend (Fig.6).

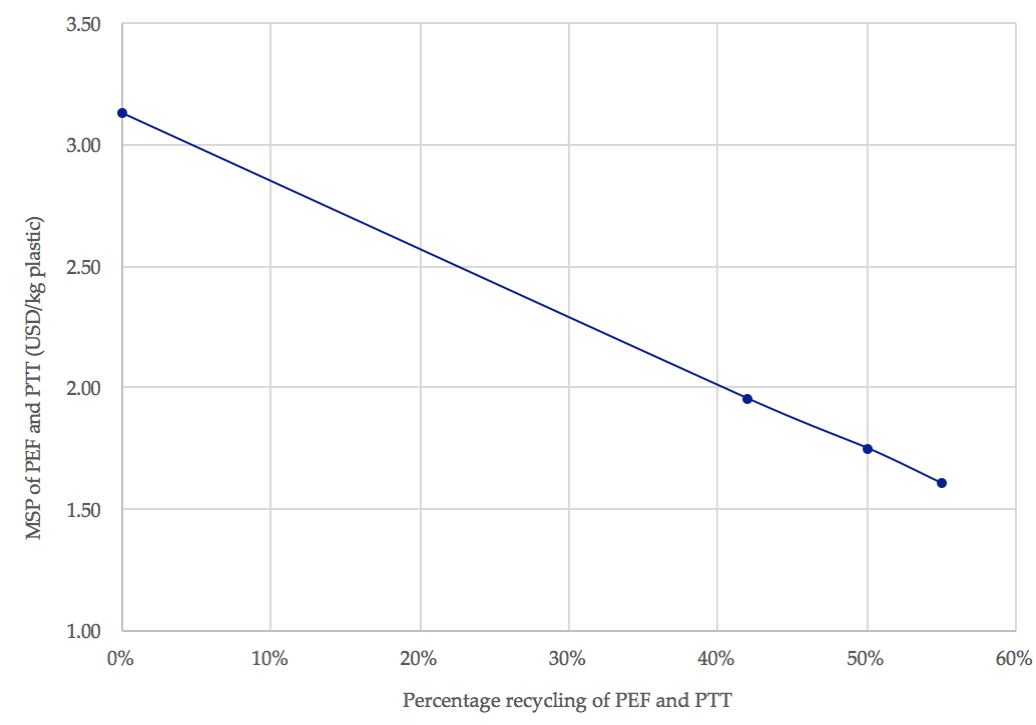

Figure 6. The MSP in USD $/ \mathrm{kg}$ of PEF and PTT with changing recycling rates $(42 \%, 50 \%$ and $55 \%$ ) of PEF and PTT.

As seen from Fig.6, recycling PEF and PTT through the process reduces the MSP of these plastics, indicating that implementing such policies would have a beneficial effect on the economic viability of the upcycled $2 \mathrm{G}$ bio-based plastics. In fact, at $55 \%$ recycling, the MSP of the plastics reaches $1.61 \mathrm{USD} / \mathrm{kg}$ (48.5\% lower than without recycling). While this is still higher than the selling price of PET, this nonetheless provides a useful strategy for making renewable plastics more competitive on the market. Notably, recycled PET has still a higher cost than the virgin one.

In addition to economic viability, it is also important to consider the environmental impacts of recycling. In fact, plastic production and incineration lead to a global production of 600 million tonnes of $\mathrm{CO}_{2}$ per year [1]. The present study does not include a life cycle analysis (LCA), which is imperative to understanding the actual benefits of this concept. However, it has been estimated that the potential annual energy savings obtained from recycling all of the plastic waste produced globally would be equivalent to 3.5 billion barrels of oil per year. This would translate into 1 million cars off the road for each million tonnes of plastic recycled [2], thus clearly showing the $\mathrm{CO}_{2}$ benefit of increased plastic recycling, which can also help reduce our dependence on fossil fuels. 
Last but not least, the impacts of this process should be compared to other means of re-utilising the PET, as well as a scenario in which the PET is recycled into itself. Further investigation into the utilisation or valorisation of the process waste streams should also be investigated. Moreover, assumptions should be carefully evaluated against full-scale real-case scenarios, and data added into the model to get a more accurate estimations.

\section{Conclusions}

This study investigated the initial profitability of a conceptual process wherein postconsumer waste PET was depolymerised and upcycled into bio-based and renewable plastics, namely PEF and PTT, which could technically be used to replace PET in the food packaging and textile industries. A techno-economic analysis of this process revealed that the majority of the operating costs lay within FDCA production for PEF synthesis, with the feedstock cost contributing the most. While 1st generation feedstocks like fructose from corn are more economically favourable, the environmental concerns around competition with food production cannot be ignored. Alternative FDCA production routes from residual streams like sugar beet pulp or wheat straw could be promising. Utilities contributed the most to the operating costs. This could be minimised by the implementation of heat integration in the process. The analysis further showed that MSP of upcycled PEF and PTT would be around $3.13 \mathrm{USD} / \mathrm{kg}$, when produced from second generation feedstock, and $2.34 \mathrm{USD} / \mathrm{kg}$ when purchasing FDCA directly. This is around three times the current PET selling price, thus suggesting that a complete substitution of PET is far from being economically feasible (with the current technology). On the other hand, the possibility of using post-consumer PET plastic waste to produce higher-value plastics at more competitive prices than the market, showed all the potential of the plastic biorefinery concept. The selling price of $4.66 \mathrm{USD} / \mathrm{kg}$ for Sorona ${ }^{\circledR}$ PTT is a clear indication for this. Moreover, it is expected that new bio-based plastics will cost more than their conventional counterparts.

Notably, adopting the European targets for recycling would have an important beneficial effect on the economic viability of the plastic biorefinery, further decreasing the MSP of the $2 \mathrm{G}$ bioplastics to $1.61 \mathrm{USD} / \mathrm{kg}$. This demonstrates that utilising post-consumer PET for bio-based plastics production, whilst simultaneously increasing plastic recycling rates, could result in a significant decrease in bio-based plastics cost, making these new plastics more competitive on the market. This should provide effective motivation for increasing recycling rates and for transitioning from fossil-based to bio-based plastics, thus showing that the plastic biorefinery concept could play an important role in the transition to a more circular plastics sector.

Overall, this study found that the plastic biorefinery concept described represents a promising approach to upcycle fossil-based plastic waste into bio-based plastics and that, though requiring further optimisation, it warrants further investigation.

Supplementary Materials: The following are available online at www.mdpi.com/xxx/s1, Table S1: Major cost inputs; Table S2: Inputs to the DCCF analysis; Table S3: Summary of capital and operating costs; Table S4: DCCF of Scenario 1; Table S5: Stream table of most important process streams; Figure S1(a): Process flow diagram of Area 1; Figure S1(b): Process flow diagram of Area 2; Figure S1(c): Process flow diagram of Area 3; Figure S1(d): Process flow diagram of Area 4; Figure S1(e): Process flow diagram of Area 5.

Funding: H2020 UPLIFT project (Grant Agreement no. 953073)

Author contribution: Conceptualization, M.R. and C.V.; methodology, M.R. and C.V.; formal analysis, M.R.; investigation, M.R. and C.V.; resources, C.V; data curation, M.R. and C.V; writingoriginal draft preparation, M.R.; writing-review and editing, M.R. and C.V; visualization, M.R.; supervision, C.V.; project administration, C.V.; funding acquisition, C.V. All authors have read and agreed to the published version of the manuscript. 
Acknowledgments: The authors wish to thank the European Commission for the financial support of this work, under H2020 Grant Agreement no. 953073 (acronym: UPLIFT). Conflicts of Interest: The authors declare no conflict of interest.

Conflicts of Interest: The authors declare no conflict of interest.

$\begin{array}{ll}\text { Abbreviations: } & \\ \text { DCCF } & \text { Discounted cumulative cash flow } \\ \text { FDCA } & \text { 2,5-furandicarboxylic acid } \\ \text { HMF } & \text { 5-hydroxymethyl furfural } \\ \text { MSP } & \text { Minimum selling price } \\ \text { PDO } & \text { 1,3-propane diol } \\ \text { PEF } & \text { Polyethylene furanoate } \\ \text { PET } & \text { Polyethylene terephthalate } \\ \text { PTT } & \text { Polytrimethylene terephthalate }\end{array}$

\section{Appendix A}

See supplementary material, Table S1-S5 and Figures S1(a)-S1(e).

\section{References}

1. McKinsey \& Company. New Plastics Economy: A research, innovation and business opportunity for Denmark 2019.

2. Narancic, T.; Cerrone, F.; Beagan, N.; O'Connor, K. E. Recent Advances in Bioplastics: Application and Biodegradation. Polymers 2020, 12(920), pp. 1-38. doi:10.3390/polym12040920.

3. Syberg, K.; Nielsen, M. B.; Clausen, L. P. W.; van Calser, G.; van Wezel, A.; Rochman, C.; Koelmans, A. A.; Cronin, R.; Pahl, S.; Hansen, S. F. Regulation of plastic from a circular economy perspective. Current Opinion in Green and Sustainable Chemistry 2021, 29, pp. 1-7. doi:10.1016/j.cogsc.2021.100462.

4. Bassi, S. A.; Boldrin, A.; Faraca, G.; Astrup, T. F. Extended producer responsibility: How to unlock the environmental and economic potential of plastic packaging waste? Resources, Conservation $\mathcal{E}$ Recycling 2020, 162, pp. 1-12. doi:10.1016/j.resconrec.2020.105030

5. World Economic Forum, Ellen Macarthur Foundation and McKinsey \& Company. The New Plastics Economy: Rethinking the Future of Plastics, 2019, London: Ellen Macarthur Foundation.

6. Hatti-Kaul, R.; Nilsson, L. J.; Zhang, B.; Rehnberg, N.; Lundmark, S. Designing Biobased Recyclable Polymers for Plastics. Trends in Biotechnology 2019, 38, pp. 1-18. doi:10.1016/j.tibtech.2019.04.011.

7. Jenkins, S.; Quer, A.M.; Fonseca, C, and Varrone, C. Microbial degradation of plastics: new plastic degraders, mixed cultures and engineering strategies. Soil microenvironment for bioremediation and polymer production. Chapter 12. Wiley Online Book. 2019. Ed. Jamil, N; Kumar, P and Batool, R. ISBN: 9781119592051.

8. European Bioplastics. Position of European Bioplastics: Plastics Strategy - Contribution of Bioplastics to a Sustainable Circular Plastics Economy 2018, Berlin: European Bioplastics.

9. Ramesh Kumar, S.; Shaiju, P.; O'Connor, K. E.; P, R. B. Bio-based and biodegradable polymers - state-of-the-art, challenges and emerging trends. Current Opinion in Green and Sustainable Chemistry 2020, 21, pp. 75-81. doi:10.1016/j.cogsc.2019.12.005.

10. Ügdüler, S.; Van Geem, K. M.; Denolf, R.; Roosen, M.; Mys, N.; Ragaert, K.; De Meester, S. Towards closed-loop recycling of multilayer and coloured PET plastic waste by alkaline hydrolysis. Green Chemistry 2020, 22, pp. 5376-5394. doi:10.1039/d0gc00894j.

11. Tournier, V.; Topham, C. M.; Gilles, A.; David, B.; Folgoas, C.; Moya-Leclair, E.; Kamionka, E.; Desrousseaux, M. -L.; Texier, H.; Gavalda, S.; Cot, M.; Guémard, E.; Dalibey, M.; Nomme, J.; Cioci, G.; Barbe, S.; Chateau, M.; André, I.; Duquesne, S.; Marty, A. An engineered PET depolymerase to break down and recycle plastic bottles. Nature 2020, 580, pp. 216-219. doi:10.1038/s41586020-2149-4.

12. Fei, X.; Wang, J.; Zhu, J.; Wang, X.; Liu, X. Biobased Poly(ethylene 2,5-furancoate): No Longer an Alternative, but an Irreplaceable Polyester in the Polymer Industry. ACS Sustainable Chem. Eng. 2020, 8, pp. 8471-8485. doi:10.1021/acssuschemeng.0c01862. 
13. Kurian, J. V. A New Polymer Platform for the Future - Sorona from Corn Derived 1,3-Propanediol. Journal of Polymers and the Environment 2005, 13(2), pp. 159-167. doi:10.1007/s10924-005-2947-7.

14. Dessbesell, L.; Souzanchi, S.; Rao, K. T. V.; Carrillo, A. A.; Bekker, D.; Hall, K. A.; Lawrence, K. M.; Tait, C. L. J.; Xu, C. Production of 2,5-furandicarboxylic acid (FDCA) from starch, glucose, or high-fructose corn syrup: techno-economic analysis. Biofuels, Bioproducts E Biorefining 2019, 13, pp. 1234-1245. doi:10.1002/bbb.2014.

15. Loos, K.; Zhang, R.; Pereira, I.; Agostinho, B.; Hu, H.; Maniar, D.; Sbirrazzuoli, N.; Silvestre, A. J. D.; Guigo, N.; Sousa, A. F.. A Perspective on PEF Synthesis, Properties, and End-Life. Frontiers in Chemistry 2020, 8, pp. 1-18. doi:10.3389/fchem.2020.00585.

16. Eerhart, A. J. J. E.; Faaij, A. P. C.; Patel, M. K. Replacing fossil based PET with biobased PEF; process analysis, energy and GHG balance. Energy \& Environmental Science 2012, 5, pp. 6407-6422. doi:10.1039/c2ee02480b.

17. Kasmi, N.; Papageorgiou, G. Z.; Achilias, D. S.; Bikiaris, D. N. Solid-State Polymerization of Poly(Ethylene Furanoate) Biobased Polyester, II: An Efficient and Facile Method to Synthesize High Molecular Weight Polyester Appropriate for Food Packaging Applications. Polymers 2018, 10(471), pp. 1-21. doi:10.3390/polym10050471.

18. Patel, M.; Angerer, G.; Crank, M.; Schleich, J.; Marscheider-Weidemann, F.; Wolf, O.; Hüsing, B. Techno-economic Feasibility of Large-scale Production of Bio-based Polymers in Europe. European Union Institute for Prospective Technological Studies Joint Research Commission, 2005, Technical Report EUR 22103 EN. ISBN: 92-79-01230-4.

19. Varrone, C.; Skiadas I. V.; Gavala, H. N. Effect of hydraulic retention time on the modelling and optimization of joint 1,3 PDO and BuA production from 2G glycerol in a chemostat process. Chemical Engineering Journal 2018, 347, pp. 525-534.

20. Eberl, A.; Heumann, S.; Kotek, R.; Kaufmann, F.; Mitsche, S.; Cavaco-Paulo, A.; Gübitz, G. M. Enzymatic hydrolysis of PTT polymers and oligomers. J Biotechnol. 2008, 135, pp. 45-51. doi:10.1016/j.jbiotec.2008.02.015

21. Bertolini, F. A.; Soccio, M.; Weinberger, S.; Guidotti, G.; Gazzano, M.; Guebitz, G. M.; Lotti, N.; Pellis, A. Unveiling the enzymatic degradation process of bio-based thiophene polyesters. Frontiers, in press.

22. Kim, H.; Choi, J.; Park, J.; Won, W. Production of a sustainable and renewable biomass-derived monomer: conceptual process design and techno-economic analysis. Green Chem. 2020, 22, pp. 7070-7079. doi:10.1039/d0gc02258f.

23. Chatzifragkou, A.; Papanikolaou, S.; Dietz, D.; Doulgeraki, A. I.; Nychas, G. E.; Zeng, A. Production of 1,3-propanediol by Clostridium butyricum growing on biodiesel-derived crude glycerol through a non-sterilized fermentation process. Applied Microbiology and Biotechnology 2011, 91, pp. 101-112. doi:10.1007/s00253-011-3247-x.

24. Petrides, D.; Da Gama, R. Production of 1,3 Propanediol (PDO) via Fermentation - Process Modeling and Techno-Economic Assessment (TEA) using SuperPro Designer 2020, Intelligen, Inc., Scotch Plains, New Jersey, USA. doi:10.13140/RG.2.2.17939.63521.

25. Seider, W. D.; Seader, J. D.; Lewin, D. R.; Widago, S. Product and Process Design Principles: Synthesis, Analysis, and Evaluation, 3rd ed.; John Wiley \& Sons, Inc., United States of America, 2009; pp. 534-627.

26. Davis, R.; Tao, L.; Tan, E. C. D.; Biddy, M. J.; Beckham, G. T.; Scarlata C.; Jacobsen, J.; Cafferty, K.; Ross, J.; Lukas, J.; Knorr, D.; Schoen, P. Process Design and Economics for the Conversion of Lignocellulosic Biomass to Hydrocarbons: Dilute-Acid and Enzymatic Deconstruction of Biomass to Sugars and Biological Conversion of Sugars to Hydrocarbons. National Renewable Energy Laboratory (NREL) Report, 2013, NREL/TP-5100-60223.

27. Intelligen, Inc. SuperPro Designer User Guide, 2020, [Online]. Available at: https://www.intelligen.com/wpcontent/uploads/2020/05/SuperPro_ManualForPrinting_v11.pdf.

28. DalinYebo. FDCA to PEF: A production cost analysis, 2019. [Online]. Available at: https://dalinyebo.com/fdca-to-pefpolyethylene-furanoate_a-production-cost-analysis/. [Accessed 21 August 2021].

29. Statista, 2021. Price of polyethylene terephthalate (PET) worldwide from 2017 to 2021, 2021. [Online]. Available at: https://www.statista.com/statistics/1171088/price- polyethylene-terephthalate-forecast-globally/. [Accessed 21 August 2021].

30. Hann, S.; Scholes, R.; Lee, T.; Ettinger, S.; Jørgensen, H. Bio-based and Biodegradable Plastics in Denmark: Market, Applications, Waste Management and Implications in the Open Environment, 2020, The Danish Environmental Protection Agency, Environmental Project No 2125, ISBN: 978-87-7038-165-9.

31. Van der Klis, F.; van Haveren, J.; van Es, D. S.; Bitter, J. H. Synthesis of Furandicarboxylic Acid Esters From Nonfood Feedstocks Without Concomitant Levulinic Acid Formation. ChemSusChem 2017, 10, pp. 1460-1468. doi:10.1002/cssc.201700051.

32. Wang, W.; Mittal, A.; Pilath, H.; Chen, X.; Tucker, M. P.; Johnson, D. K. Simultaneous upgrading of biomass-derived sugars to HMF/furfural via enzymatically isomerized ketose intermediates. Biotechnol Biofuels 2019, 12(253), pp. 1-9. doi:10.1186/s13068019-1595-4.

33. Varrone C.; Liberatore R.; Crescenzi C.; Izzo G.; Wang, A. J. The valorization of glycerol: experimentation and economic assessment of an innovative process for the bioconversion of crude glycerol into ethanol and hydrogen. Applied Energy 2013, 105, pp. 349-357.

34. Fernando-Foncillas, C.; Varrone, C. Potential of the sewage sludge valorization in Scandinavia by co-digestion with other organic wastes: a Techno-economic assessment. Journal of Cleaner Production 2021, 324, pp. 129-139

35. European Commission. A European Strategy for Plastics in a Circular Economy. 2018, Brussels, 16.1.2018.COM.

36. Eurostat. Plastic packaging recycling rate, electronic dataset, 2017. URL: https://ec.europa.eu/eurostat/databrowser/view/ten00063/default/table?lang=en. 